\title{
Effects of an Algorithm-based Education Program on Nursing Care for Children with Epilepsy by Hospital Nurses
}

\author{
Jung Hwa Lee ${ }^{1}$, Hyeon Ok Ju², Yun Jin Lee ${ }^{3}$ \\ ${ }^{1}$ Registered Nurse, Pusan National University Yangsan Hospital, Yangsan; ${ }^{2}$ Professor, Department of Nursing, Dong-A University, Busan; \\ ${ }^{3}$ Associate Professor, Department of Pediatrics, Pusan National University Children's Hospital, School of Medicine, Pusan National University, Yangsan, Korea
}

Purpose: Epilepsy is the most common neurological disorder in childhood. Hospital nurses, who are the first to recognize seizures in epilepsy patients in the ward environment, possess expertise related to epilepsy and play a central role in epilepsy management. The purpose of this study was to develop an algorithm-based education program and to improve nurses' knowledge and self-efficacy related to providing nursing care to children with epilepsy. Methods: The education program consisted of lectures on the definition, cause, classification, diagnosis, treatment, and nursing of epilepsy based on a booklet, as well as practice using an algorithm for nursing interventions when a child experiences a seizure. Twenty-seven nurses working at pediatric neurological wards and a pediatric emergency room participated in the education program. The data were analyzed using descriptive statistics and the paired t-test. Results: Nurses' knowledge and self-efficacy showed a statistically significant improvement after participation in the education program on nursing care for children with epilepsy. Conclusion: The application of this education program for hospital setting is expected to improve nurses' capability to care for children with epilepsy, thereby contributing to a higher quality of nursing.

Key words: Epilepsy; Seizure; Nursing education; Nurses

\section{Corresponding author Hyeon Ok Ju}

https://orcid.org/0000-0002-0264-2651

Department of Nursing, Dong-A University,

32 Daesingongwon-ro, Seo-gu, Busan 49201, Korea

TEL +82-51-240-2689 FAX +82-51-240-2920

E-MAIL enfanju@dau.ac.kr

*This article was adapted from a thesis by Jung Hwa Lee in partial fulfillment of the requirements for the master's degree at Dong-A University.

Received May 16, 2019 Revised Jun 21, 2019 Accepted Jul 3, 2019 (a) This is an Open Access article distributed under the terms of the Creative Commons Attribution NonCommercial License (http://creativecommons.org/licenses/by-nc/4.0/) which permits unrestricted noncommercial use, distribution, and reproduction in any medium, provided the original work is properly cited.

\section{INTRODUCTION}

\section{Need for Study}

A seizure is a transient occurrence of signs or symptoms resulting from excessive or synchronous neuronal activity in the brain. Epilepsy is to be considered present when two or more unprovoked seizures occur in a time frame of longer than 24 hours [1]. Approximately $4 \sim 10 \%$ of children experience at least one seizure in the first 16 years of life. The cumulative lifetime incidence of epilepsy is 3\%, and the disorder starts in childhood in more than half of cases [2]. A Korean epidemiological report on epilepsy showed that among individuals aged less than 60 years, the prevalence of epilepsy was highest among those aged $5 \sim 9$ ( 4.8 boys and 5.8 girls out of 1,000$)$, followed by those aged $0 \sim 4$ ( 4.2 boys and 5.4 girls out of 1,000$)$ [3].

Epilepsy is the most frequent neurological disorder in childhood. Because epilepsy in childhood occurs in the setting of a cerebral structure characterized by quicker development and greater vulnerability than in adulthood, and it can lead to lifethreatening or fatal results, making it crucial to detect and treat epilepsy properly in its early stages [2]. Of particular 
concern, status epilepticus is defined either as a seizure that persists for more than 30 minutes or as incomplete recovery of consciousness between episodes of recurrent seizure. Because status epilepticus may be a neurological emergency, it is necessary to provide proper treatment and nursing interventions rapidly [4]. If appropriate treatment is not given, affected children can experience serious sequelae, such as permanent neurological malfunction or intractable epilepsy, and are at a high risk for death [5].

Clinical nurses, who are the first to recognize seizures in epilepsy patients in the ward environment, must know the possible complications and risks of seizure, acquire expertise related to epilepsy, and play a central role in epilepsy management [6]. Because individual patients can have different types of seizures, nurses need to recognize the seizure-causing factors and provide patient-centered nursing [6]. In the United Kingdom, nurses take charge of disease management, counseling, and education for patients with epilepsy, are aware of the guidelines for dosage of anticonvulsants, and prevent and manage their distress or problems $[7,8]$. When a patient with epilepsy has a seizure, a nurse can give correct information to the doctor and the caregiver and perform the primary intervention. To do this, nurses must have extensive education on evidence-based epilepsy management, as well as guidelines or protocols for correct and systematic nursing interventions in cases of seizure in a child with epilepsy $[6,9,10]$.

Most of the guidelines for the management of children with epilepsy focus on the type and dosage of drugs and medical treatment when a seizure occurs and lack detailed information about nursing care $[5,11]$. As such, nurses may experience difficulty in applying these guidelines to the nursing care of children with epilepsy. Nurses regard seizure precautions as preparation for resuscitation equipment, regardless of seizure type. For children with staring spells lasting 5 seconds, if they have not been weaned off anti-epileptic medications, neither a bag nor a mask is required because there is no risk of respiratory compromise [9]. However, if symptoms such as cyanosis and secretion occur, as well as in generalized secondary tonic-clonic seizures, it is crucial to have proper equipment next to the bed [9].

According to a study on educational strategies for improving knowledge and skills among ward nurses [12], the most frequently applied learning strategies were experiential methods such as simulations and role play. However, simulatorbased education requires resources and manpower [12]. In contrast, algorithms consist of a finite sequence of well-defined instructions, that are systematically performed, and are commonly used in healthcare [13]. Providing a complete view of the clinical process, these instruments are simple, direct, and easy-to-access, functioning as a guide for decision-mak- ing [13]. Clore [9] contended that an algorithm for giving safe and systematic nursing would be effective against epileptic seizure.

South Korea has few systematic nursing guidelines or education programs related to pediatric epilepsy, although nurses play a crucial role in treating children with epilepsy. Therefore, it is important that hospital nurses caring for children with epilepsy are provided with a structured education program to improve their knowledge on pediatric epilepsy and self-efficacy in caring for pediatric patients with epilepsy.

\section{Objectives}

The purpose of this study was to develop an algorithmbased education program for hospital nurses caring for children with epilepsy and to investigate the effects of the education program.

\section{Hypotheses}

1) Hospital nurses would have better knowledge of epilepsy after participation in the education program.

2) Hospital nurses would have better self-efficacy related to caring for children with epilepsy after participation in the education program.

\section{METHODS}

\section{Study Design}

This study used a pre-test and post-test design to evaluate the effectiveness of an algorithm-based education program on nurses' knowledge of epilepsy and self-efficacy related to caring for children with epilepsy.

\section{Participants}

The participants in this study were nurses working in wards for the hospitalization of children with neurological disease at P National University Children's Hospital, Y city. They had more than 6 months of nursing experience, had personally provided nursing care to children with epilepsy, understood the purpose of this study, and participated voluntarily. The sample size was estimated using G-Power version 3.1.9.2. A sample size of 24 persons was calculated with an effect size of .60 [14] and testability of .80 at the .05 significance level on the basis of the paired two-sided t-test. This study was conducted among 27 persons, taking a dropout rate of $10 \%$ into consideration. 


\section{Development of the Education Program}

\section{1) Interview on educational needs}

Interviews were performed with nurses to determine their educational needs, with the objective of developing an education program for providing nursing care to children with epilepsy. Eight nurses with at least 3 years of clinical experience in pediatric neurological wards, who were considered competent according to the Korean career ladder [15], were recruited through purposive sampling from May 1 to 12, 2017. Individual interviews were conducted by one researcher using a conversational-style interview technique and a semi-structured interview guide that included questions such as "What difficulties have you experienced when nursing children with epilepsy?" and "What education do you think is necessary for nursing children with epilepsy?". The interviews were performed and audio-recorded in the counseling room in the ward taking accessibility and convenience into account. The interviews lasted an average of 30 minutes. The audio-recorded interviews were transcribed verbatim and recurrent significant phrases from the transcripts were coded. Then, all data within a particular code were analyzed based on the fre- quency of occurrence in the text and were merged to form categories.

The interview indicated that the highest educational need of nurses was for nursing interventions during seizures in children with epilepsy, followed by information on treatment and nursing interventions according to seizure types, medication and side effects. Other areas were how to educate caregivers and how to communicate with medical staff and caregivers.

\section{2) Education program for providing nursing care to children with epilepsy}

An education program for providing nursing care to children with epilepsy was developed on the basis of the interviews about educational needs and a literature review $[6,10,16,17]$ (Table 1). It was designed to improve nurses' knowledge of epilepsy in children and to make good use of nursing interventions when children with epilepsy experience a seizure. The teaching materials were developed before initiating the education program. Content regarding the definition, causes, classification, diagnosis, treatment, and nursing of epilepsy was developed in the form of a booklet. The

Table 1. Education Program on Nursing Care for Children with Epilepsy

\begin{tabular}{|c|c|c|c|c|c|c|}
\hline Learning objective & Methods & Subject & Contents or Methods & Materials & $\begin{array}{l}\text { Duration } \\
\text { (minute) }\end{array}$ & Evaluation \\
\hline $\begin{array}{l}\text { To understand the } \\
\text { definition and cause } \\
\text { of epilepsy }\end{array}$ & Lecture & Introduction & $\begin{array}{l}\text { - Definitions and causes of epilepsy } \\
\text { - Terms currently used by clinicians }\end{array}$ & $\begin{array}{l}\text { Booklet } \\
\text { Powerpoint }\end{array}$ & 5 & $\begin{array}{l}\text { Knowledge } \\
\text { of epilepsy }\end{array}$ \\
\hline $\begin{array}{l}\text { To understand the } \\
\text { classification of } \\
\text { epilepsy and common } \\
\text { seizures in children }\end{array}$ & Lecture & Classification & $\begin{array}{l}\text { - Classification of epilepsy } \\
\text { - Generalized/focal seizures } \\
\text { - Common seizures in children } \\
\text { - West syndrome/Lennox-Gastaut } \\
\text { syndrome/Status epilepticus }\end{array}$ & $\begin{array}{l}\text { Booklet } \\
\text { Powerpoint }\end{array}$ & 15 & $\begin{array}{l}\text { Knowledge } \\
\text { of epilepsy }\end{array}$ \\
\hline $\begin{array}{l}\text { To understand the } \\
\text { definition and cause } \\
\text { of epilepsy }\end{array}$ & Lecture & $\begin{array}{l}\text { Diagnosis and } \\
\text { treatment }\end{array}$ & $\begin{array}{l}\cdot \text { Diagnostic method } \\
\text { - Listen to patient's history/EEG/MRI } \\
\cdot \text { Medication/ketone diet/surgical } \\
\text { treatment }\end{array}$ & $\begin{array}{l}\text { Booklet } \\
\text { Powerpoint }\end{array}$ & 10 & $\begin{array}{l}\text { Knowledge } \\
\text { of epilepsy }\end{array}$ \\
\hline $\begin{array}{l}\text { To understand nursing } \\
\text { interventions during } \\
\text { seizure of children } \\
\text { with epilepsy }\end{array}$ & Lecture & $\begin{array}{l}\text { Nursing for } \\
\text { children with } \\
\text { epilepsy }\end{array}$ & $\begin{array}{l}\text { Nursing interventions during seizure } \\
\text { of children with epilepsy } \\
\text { - Nursing by type of seizure using the } \\
\text { algorithm developed in this study } \\
\text { - Frequently asked questions by parents }\end{array}$ & $\begin{array}{l}\text { Booklet } \\
\text { Powerpoint }\end{array}$ & 10 & $\begin{array}{l}\text { Knowledge } \\
\text { of epilepsy }\end{array}$ \\
\hline $\begin{array}{l}\text { To practice nursing } \\
\text { interventions during } \\
\text { seizure in children } \\
\text { with epilepsy }\end{array}$ & Practice & $\begin{array}{l}\text { Nursing } \\
\text { practice during } \\
\text { seizure using } \\
\text { algorithm }\end{array}$ & $\begin{array}{l}\text { - Demonstrate } \\
\text { - Show a seizure video for } 1 \sim 2 \mathrm{~min} \\
\text { - Demonstrate nursing interventions } \\
\text { according to the algorithm } \\
\text { - Volunteer practice } \\
\text { - Show a seizure video for } 1 \sim 2 \mathrm{~min} / \\
\text { Three volunteers' practice }\end{array}$ & $\begin{array}{l}\text { Oxygen } \\
\text { Suction } \\
\text { Fall guard } \\
\mathrm{SaO}_{2} \text { monitor }\end{array}$ & 20 & $\begin{array}{l}\text { Self-efficacy } \\
\text { in nursing }\end{array}$ \\
\hline
\end{tabular}

EEG=Electroencephalogram; MRI=Magnetic resonance imaging; $\mathrm{SaO}_{2}=$ Oxygen saturation . 
content regarding nursing care in cases of seizure in children with epilepsy, for which the nurses expressed the highest level of educational need, was developed in the form of an algorithm that provided guidance on the most appropriate nursing intervention based on the type of seizure, with the aim of making the material more applicable.

(1) Booklet

A booklet was developed by the authors for training nurses on how to provide nursing care for children with epilepsy. It was composed of 20 pages and covered the definition and causes of epilepsy, its classification and common types of seizures, and its diagnosis, treatment, and nursing care. The contents were presented in simple figures and charts so that nurses could easily understand and apply them. The booklet was evaluated by a professor of child nursing at the first step. Some of the initial educational content was not for nurses, but for parents of children with epilepsy; based on feedback at this stage, all materials were changed to provide educational content for nurses. The booklet was then evaluated by a pediatric neurologist and three nurses with more than 5 years of career experience in nursing children with epilepsy, and no further revisions were made.
(2) Algorithm for nursing interventions in cases of seizure in children with epilepsy

Algorithms have been reported to be effective in teaching the proper nursing methods for children with epilepsy, as nurses have a high level of need for a systematic nursing intervention method to apply in cases of seizure [9]. A nurse, who had worked for more than 7 years in a pediatric neurological ward and a pediatric neurologist developed an algorithm for nursing interventions when seizures occur in children with epilepsy in hospital settings. This algorithm was evaluated by a professor of child nursing and four nurses with more than 5 years of experience in nursing children with epilepsy, and was not modified at all. The algorithm for nursing intervention during seizure for children with epilepsy was applicable to clinical practice to serve as an available guideline to consult when patients experienced difficulty in breathing (Figure 1).

A nurse needs to determine the type of seizure and difficulty in breathing experienced by a child and to inform the appropriate doctor of it. If the child has difficulty in breathing or has a generalized tonic-clonic seizure, it is necessary to secure an airway, locate a venous line, and prepare a primary anticonvulsant. If a child experiences seizure without difficulty in breathing, it is necessary to observe airway maintenance sta-

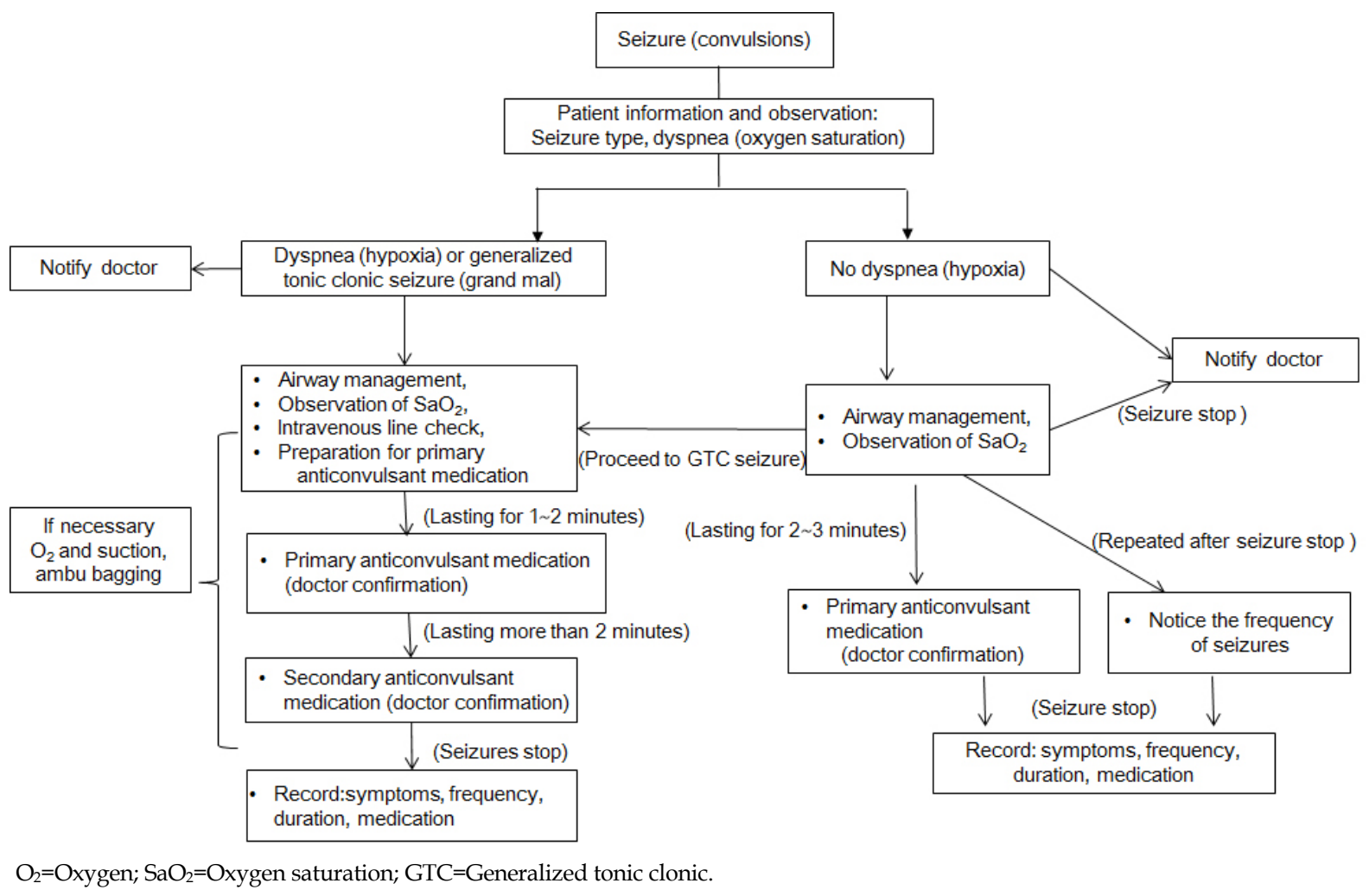

Figure 1. Algorithm for nursing interventions during seizures in children with epilepsy. 
tus and oxygen saturation. The appropriate nursing intervention based on the type of seizure was detailed in the form of different pathways within the algorithm.

\section{Intervention}

The education site and time were determined with the cooperation of the educator in the department of nursing at the hospital and the nurse manager of each ward, and one education was conducted in a seminar room within the hospital in a group setting. The material on the definition, classification, diagnosis and treatment of pediatric epilepsy was taught by a pediatric neurologist for 30 minutes, while the material on nursing care for children with epilepsy was taught for 10 minutes by a nurse, using the booklet developed by the researchers.

The participants practiced with nursing interventions during seizure for 20 minutes. First of all, a researcher showed two YouTube videos (https://youtu.be/vSnRdmR6xcE, https:// youtu.be/TcSegvM0qOk) of children having a seizure (with or without difficulty in breathing), and she demonstrated the appropriate nursing intervention for each type of seizure according to the algorithm developed in this study. The seizure videos took 1 or 2 minutes. Due to time constraints, only three nurses were called upon to apply what they watched from the video clips in order to practice nursing interventions by type of seizure.

After the education session, the booklets were placed in each ward, and the algorithm for nursing during seizures in children with epilepsy was posted on the bulletin board of the ward to encourage the nurses to review th material at any time.

\section{Instruments}

\section{1) General characteristics}

The participants' general characteristics assessed using the questionnaire included age, marital status, educational level, and clinical experience.

\section{2) Knowledge of epilepsy}

A tool for measuring knowledge of epilepsy in childhood was developed by the researcher on the basis of a literature review $[1,16,17]$. It was tested for content validity by a pediatric neurologist, a professor of child nursing, and three nurses who had worked for more than 10 years in pediatric neurological wards. Its content validity was confirmed, as the content validity index (CVI) was more than .80 for each of the 10 items.

This tool has a total of 10 items: one on the definition of epilepsy, one on its causes, three on its classification, one on its diagnosis, one on its treatment, one on its medication, and two on nursing care for epilepsy. A score of 10 is given for each right answer, and a score of 0 is given for wrong answers, yielding a potential total score of 100 .

\section{3) Self-efficacy in nursing children with epilepsy}

Yang's [18] Korean translation of the general self-efficacy scale developed by Sherer and Adams [19] and revised by Sherer et al. [20] was adapted to providing nursing care for children with epilepsy in this study. It was tested for content validity by a professor and a doctoral candidate of child nursing, along with three nurses who had worked for more than 10 years in pediatric neurological wards. It exhibited content validity, with the CVI being 1.00 for all items.

This tool contains a total of 14 items on a 4-point Likert scale, with higher scores indicating a higher level of self-efficacy. The range of scores is 4 to 56 .

Cronbach's $\alpha$, a reliability coefficient, was calculated to be .79 in the study of Yang [18] and to be .77 in this study.

\section{Data Collection}

The data were collected from August 25 to September 1, 2017. A notification was posted on the bulletin board of the ward to attract participants with the nurse manager's cooperation. In total, 27 nurses consenting to participate in this study were personally given an explanation about its purpose and methods by the researcher and were asked to provide a written consent. Before the education session, a pretest was performed to determine the general characteristics of the participants, their knowledge of epilepsy, and their selfefficacy. Post-tests were performed to evaluate the nurses' knowledge of epilepsy and self-efficacy, immediately after the end of the education session and 1 week after the education session. The second post-test was performed 1 week after the education session on the basis of the Ebbinghaus forgetting curve, according to which approximately $75 \%$ of memory loss occurs within 6 days [21].

\section{Ethical Considerations}

This study received approval from the Institutional Review Board of P Hospital (05-2017-086). The participants were given a full explanation of the purpose of the study, the education program, and research methods before they gave their approval. They were given an explanation stating that participation was not obligatory and that they could withdraw from participation at any time without any disadvantage. Every detail of the survey remained anonymous. Before providing written consent, participants received an explanation that the data from the survey would not be used for any other purpose 
than the study. Every participant was given a token gift as remuneration.

\section{Data Analysis}

The collected data were analyzed using SPSS for Windows version 21.0 (IBM Corp., Armonk, NY, USA). Frequency, percentage, and the mean and standard deviation were used to present the nurses' general characteristics, knowledge about epilepsy, and self-efficacy. The paired t-test was carried out before and after the educational intervention to analyze the nurses' knowledge of epilepsy and self-efficacy. All p-values were adjusted using the Bonferroni correction.

\section{RESULTS}

\section{Participants' General Characteristics}

Table 2 summaries the participants' characteristics. The majority of the participants were single $(77.8 \%)$ with an average age of 27.3 years. Most of them (77.8\%) had a university education or higher, while $66.7 \%$ had less than 5 years of working experience.

\section{Hypotheses Testing}

\section{1) Testing of hypothesis 1}

Hypothesis 1 stated that clinical nurses would have better knowledge about nursing care for children with epilepsy after

Table 2. Demographic Characteristics of Participants $\quad(N=27)$

\begin{tabular}{llrr}
\hline Characteristics & Categories & $\mathrm{n}(\%)$ & $\mathrm{M} \pm \mathrm{SD}$ \\
\hline Marital status & Single & $21(77.8)$ & \\
& Married & $6(22.2)$ & \\
Age (year) & Under 26 & $8(29.6)$ & $27.3 \pm 3.6$ \\
& 26 and over & $19(70.4)$ & \\
Educational level & College & $6(22.2)$ & \\
& $\geq$ University & $21(77.8)$ & \\
Work experience & $\leq 5$ & $18(66.7)$ & $51.9 \pm 43.8$ \\
$\quad$ (year) & $\geq 6$ & $9(33.3)$ & \\
\hline
\end{tabular}

participation in the algorithm-based education program. Statistically significant differences in the nurses' knowledge of epilepsy were found before and after participation in the education program. Hypothesis 1 was supported (Table 3). Their knowledge significantly improved after their participation in the education program, from $69.63 \pm 20.09$ to $91.48 \pm 8.64(t=$ 5.84, $p<.001$ ). A week later, their knowledge also showed a significant improvement, as they scored 93.70 \pm 7.41 at the post-test conducted 1 week after participation in the education program $(\mathrm{t}=6.70, p<.001)$.

\section{2) Testing of hypothesis 2}

Hypothesis 2 stated that clinical nurses would have better self-efficacy related to providing nursing care to children with epilepsy after participation in the algorithm-based education program. Statistically significant differences were found in the nurses' self-efficacy before and after participation in the education program. Hypothesis 2 was supported (Table 3). Their self-efficacy related to providing nursing care to children with epilepsy significantly improved after their participation in the education program, from $39.33 \pm 8.49$ to 42.89 $\pm 5.29(\mathrm{t}=3.32, p=.006)$. A week later, their self-efficacy also showed a significant improvement with a score of $46.80 \pm 5.95$ $(\mathrm{t}=5.48, p<.001)$.

\section{DISCUSSION}

Nurses caring for children with epilepsy should be well-informed about the nature of epilepsy, and should be prepared to carry out professional nursing interventions without panicking when a child experiences a seizure. However, South Korea has few pediatric epilepsy-related studies or education programs for nurses who work in pediatric neurological wards. As a result, it is difficult for them to provide safe and systematic nursing care to children with epilepsy in cases of seizure. The purpose of this study was to improve nurses' knowledge of epilepsy and self-efficacy related to caring for children with epilepsy by providing them with an algorithm-based education program about how to care for children with epilepsy.

A major advantage of this study is that the educational materials were developed based on nurses' needs. The area for which the nurses expressed the highest level of educational

Table 3. Effects of the Education Program on the Nursing Care of Children with Epilepsy

\begin{tabular}{|c|c|c|c|c|c|}
\hline \multirow{2}{*}{ Variables } & Pretest & Posttest 1 & Posttest 2 & \multirow{2}{*}{$t^{*}\left(p^{\dagger}\right)$} & \multirow{2}{*}{$\mathrm{t}^{\dagger}\left(p^{\dagger}\right)$} \\
\hline & $\mathrm{M} \pm \mathrm{SD}$ & $\mathrm{M} \pm \mathrm{SD}$ & $\mathrm{M} \pm \mathrm{SD}$ & & \\
\hline Knowledge & $69.63 \pm 20.09$ & $91.48 \pm 8.64$ & $93.70 \pm 7.41$ & $5.84(<.001)$ & $6.70(<.001)$ \\
\hline Self-efficacy & $39.33 \pm 8.49$ & $42.89 \pm 5.29$ & $46.80 \pm 5.95$ & $3.32(.006)$ & $5.48(<.001)$ \\
\hline
\end{tabular}

*Posttest 1 - Pretest; ${ }^{\dagger}$ Posttest 2 - Pretest; ${ }^{\dagger} p$ values were adjusted using the Bonferroni correction. 
needs was nursing care during seizures in children with epilepsy. Many researchers [6,9] have reported that the appropriate nursing care during seizures in children with epilepsy depends on the type of seizure. Thus, different nursing interventions should be applied to different types of seizures, and content describing appropriate nursing care during seizures in children with epilepsy was developed in the form of an algorithm so that nurses could learn them with ease.

Algorithms are simple and easily communicate the nursing process in any healthcare system [13]. In addition, training using the algorithm developed in this study could prove efficient in terms of time and cost because education using simulators requires a great quantity of resources and manpower [12]. In medicine, several studies have explored algorithmbased education $[13,22]$, but in nursing there is a lack of research on this topic. This study will contribute to expanding algorithm-based education programs to help nurses make decisions.

Before the education program, the nurses scored relatively low (an average of 69.63 out of 100) for knowledge on epilepsy. Dayapoglu and Tan [10], who investigated epilepsy-related knowledge and attitude in 96 nurses, found that they scored an average of 78.8 out of 100 for knowledge about epilepsy. Therefore, it seems to be essential to establish a systematic continuing nursing education program to improve nurses' knowledge and skills in caring for children with epilepsy in hospital settings.

The nurses scored higher for knowledge of epilepsy immediately after participating in the education program for the nursing of children with epilepsy, and the effect lasted for a week. Stecker [23] provided 25 nurses with an epilepsy-related education program using a case-based scenario and showed improvements in their assessment scores for epilepsy patients. Dworetzky et al. [24] provided nurses and residents with a simulation-based team -training curriculum that improved their scores for epilepsy-related knowledge and attitude. The training program in this study was a group-based education session for 27 nurses; however, as with education using case- or -simulation-based scenarios, it improved the nurses' knowledge of epilepsy and self-efficiency.

The scores for knowledge remained higher after nurses participated in the education program because the nurses' needs were reflected, an algorithm known to be easy to access in the clinical setting was utilized in the education program and was posted on the bulletin board in each ward, and an educational booklet was placed at an accessible site to enable repetitive learning. Therefore, the reinforcement of existing materials could guide nurses in caring for children with epilepsy.

The nurses scored higher for self-efficacy related to providing nursing care for children with epilepsy immediately after their participation in the education program, and the scores remained elevated a week later. Auberry and Cullen [25], who applied an evidence-based seizure algorithm to nurses in the field of intellectual disability, reported that they became more confident in telephone triage. Kim, Chun, and Park [26], who provided 25 nurses with a 20 -week education program composed of a combination of theoretical and practical training in hemodialysis nursing, also found that their self-efficacy related to hemodialysis nursing improved after the program.

In nursing, self-efficacy is important as a preceding factor for behavior. Self-efficacy is defined as reliance on one's ability to successfully perform acts necessary to achieve a certain task $[27,28]$. Self-efficacy refers to one's perception of the ability to perform and is central to the transition between knowledge and behavior [27]. Increasing self-efficacy in nursing practice may improve nurses' professional practice behaviors [29]. Numerous studies have found that higher levels of self-efficacy related to nursing practice are associated with higher levels of professional practice behaviors and job satisfaction $[29,30]$. Therefore, it is believed that this algorithmbased education program about nursing care for children with epilepsy can help hospital nurses improve their self-efficacy, and nursing competence related to children with epilepsy.

Although this study has implications for developing algorithm-based educational materials that are accessible and effective for nurses who care for children with epilepsy, it has some limitations. It is difficult to generalize the results of this study because it was conducted among nurses at a single hospital; another limitation is that it failed to have a control group due.

\section{CONCLUSION}

This study utilized a pre-test and post-test design to identify the effects of an algorithm-based education program on hospital nurses' epilepsy-related knowledge and self-efficacy. The educational materials were developed through a interview with nurses on the educational needs and a literature review. The content of the educational booklet included the definition, classification, diagnosis, treatment, and nursing of epilepsy. Nursing care was developed in the form of an accessible algorithm for nurses to apply in cases of seizure in children with epilepsy, which was the area where the educational needs of the nurses were highest.

This study is significant in that it developed an education program for hospital nurses caring for children with epilepsy, along with YouTube videos and an algorithm-based practical training program, which improved participants' knowledge of epilepsy and self-efficacy in providing nursing care for children with epilepsy, a population for which limited nurs- 
ing protocols and guidelines.

The following suggestions can be made:

First, It is necessary to study whether the effect of the algorithm- based education program for the nursing of children with epilepsy lasts longer than 1 month using a randomized control group design.

Second, It is necessary to encourage self-directed learning by nurses who care for children with epilepsy as part of further research on the development and effects of a web-based education program.

\section{Conflict of interest}

No existing or potential conflict of interest relevant to this article was reported.

\section{REFERENCES}

1. Kliegman R, Stanton B, Behrman RE, St Geme JW, Schor NF, Nelson WE. Nelson textbook of pediatrics. Philadelphia, PA: Elsevier; 2016. p. 3086-3120.

2. Aaberg KM, Gunnes N, Bakken IJ, Lund Søraas C, Berntsen A, Magnus P, et al. Incidence and prevalence of childhood epilepsy: A nationwide cohort study. Pediatrics. 2017;139(5):e20163908.

https://doi.org/10.1542/peds.2016-3908

3. Korean Epilepsy Society. Epidemiological study of seizure and epilepsy using nationwide database for Corean epilepsy patients (ESSENCE) [Internet]. Seoul: Korean Epilepsy Society; 2012 [cited 2017 Jan 5]. Available from:

http://www.medric.or.kr/Uploads/BLibrary/\%EB\%87\%8C\%EC \%A0\%84\%EC\%A6\%9D \% 20\%EC\%97\%AD\%ED\%95\%99\%20\%EC \%A1\%B0\%ЕC\%82\%AC\%20\%ЕB\%B3\%B4\%ЕA\%B3\%A0\%ЕC\%84 $\% 9 \mathrm{C}(\% \mathrm{EA} \% \mathrm{~B} 0 \% 9 \mathrm{C} \% \mathrm{EC} \% \mathrm{A0} \% 95)$.pdf.

4. Huh KH, Song KH, Cho OY, Sim JH, Cho DJ, Kim DH, et al. A clinical study of acute symptomatic seizures in children. Journal of Korea Child Neurology Society. 2002;10(1):94-102.

5. Glauser T, Shinnar S, Gloss D, Alldredge B, Arya R, Bainbridge J, et al. Evidence-based guideline: Treatment of convulsive status epilepticus in children and adults: Report of the guideline committee of the American Epilepsy Society. Epilepsy Currents. 2016;16(1):48-61. https://doi.org/10.5698/1535-7597-16.1.48

6. Spay J. Seizures: Awareness and observation in the ward environment. British Journal of Nursing. 2015;24(19):946-955. https://doi.org/10.12968/bjon.2015.24.19.946

7. Foley J, Oates J, Mack C, Fox C. Improving the epilepsy service: The role of the specialist nurse. Seizure. 2000:9(1);36-42. https://doi.org/10.1053/seiz.1999.0365

8. Hosking PG. The specialist nurse role in the treatment of refractory epilepsy. Seizure. 2004;13(5):303-307. https://doi.org/10.1016/j.seizure.2003.08.001
9. Clore ET. Seizure precautions for pediatric bedside nurses. Pediatric Nursing. 2010;36(4):191-194.

10. Dayapoğlu N, Tan M. Clinical nurses' knowledge and attitudes toward patients with epilepsy. Epilepsy and Behavior. 2016;61: 206-209. https://doi.org/10.1016/j.yebeh.2016.05.009

11. National Institute for Health and Care Excellence. Epilepsies: Diagnosis and management(CG137) [Internet]. London: National Institute for Health and Care Excellence; 2012 [cited 2017 Jan 20]. Available from: https://www.nice.org.uk/guidance/cg137.

12. Liaw SY, Scherpbier A, Klainin-Yobas P, Rethans JJ. A review of educational strategies to improve nurses' roles in recognizing and responding to deteriorating patients. International Nursing Review. 2011;58(3):296-303. https://doi.org/10.1111/j.1466-7657.2011.00915.x

13. Cunha DRD, Salomé GM, Massahud MR Junior, Mendes B, Ferreira LM. Development and validation of an algorithm for laser application in wound treatment. Revista Latino-Americana de Enfermagem. 2017;25:e2955. https://doi.org/10.1590/1518-8345.1998.2955

14. Jeoung Y, Bak YI, Lee J, Park S, Jin J, Lee H, et al. Effects of an education program for effective nursing intershift handoff communication on nurses' intershift performance, self-efficacy, and interrelationship stress among clinical nurses: A pilot study. Journal of Korean Academy of Psychiatric and Mental Health Nursing. 2016; 25(3):176-186. https://doi.org/10.12934/jkpmhn.2016.25.3.176

15. Park SH, Park KO, Park SA. A development of career ladder program for nurse in a hospital. Journal of Korean Academy of Nursing Administration. 2006;12(4):624-632.

16. Gambrell M, Flynn N. Seizures 101. Nursing. 2004;34(8):36-42.

17. Korean Child Neurology Society. Pediatric neurology. 2nd ed. Seoul: Koonja; 2013. p. 175-230.

18. Yang KM. Analysis of the relationship between the empowerment, the job-related individual characteristics and the work performance of nurses [dissertation]. Seoul: Kyung Hee University; 1999. p. 1-77.

19. Sherer M, Adams CH. Construct validation of self-efficacy scale. Psychological Reports. 1983;53(3):899-902.

https://doi.org/10.2466/pr0.1983.53.3.899

20. Sherer M, Maddux JE, Mercandante B, Prentice-Dunn S, Jacobs B, Rogers RW. The self-efficacy scale: Construction and validation. Psychological Reports. 1982:51(2):663-671. https://doi.org/10.2466/pr0.1982.51.2.663

21. Ebbinghaus H. Memory: A contribution to experimental psychology. 1st ed. Eastford: Martino Fine Books; 2011. p. 1-123.

22. Amini R, Stolz L, Kartchner J, Thompson M, Stea N, Hawbaker N, et al. Bedside echo for chest pain: An algorithm for education and assessment. Advances in Medical Education and Practice. 2016;7: 293-300. https://doi.org/10.2147/AMEP.S103083

23. Stecker M. The effect of education on nurses' assessments in an epilepsy monitoring unit. Canadian Journal of Neuroscience Nursing. 
2012;34(2):23-32.

24. Dworetzky BA, Peyre S, Bubrick EJ, Milligan TA, Yule SJ, Doucette $\mathrm{H}$, et al. Interprofessional simulation to improve safety in the epilepsy monitoring unit. Epilepsy and Behavior. 2015;45:229-233. https://doi.org/10.1016/j.yebeh.2015.01.018

25. Auberry K, Cullen D. Implementation of an evidence-based seizure algorithm in intellectual disability nursing: A pilot study. Journal of Intellectual Disabilities. 2016:20(1):55-64.

https://doi.org/10.1177/1744629515598216

26. Kim Y, Chun IS, Park YM. Development of a hemodialysis nurse educational program and its effects. Journal of the Korea Academia-Industrial cooperation Society. 2012;13(12):5839-5848.

https://doi.org/10.5762/KAIS.2012.13.12.5839
27. Bandura A. Self-efficacy: Toward a unifying theory of behavioral change. Advances in Behaviour Research and Therapy. 1978;1(4): 139-161.

28. Bandura A, Adams NE. Analysis of self-efficacy theory of behavioral change. Cognitive Therapy and Research. 1977;1(4):287-310.

29. Manojlovich M. Promoting nurses' self-efficacy: A leadership strategy to improve practice. The Journal of Nursing Administration. 2005;35(5):271-278.

30. De Wandel D, Maes L, Labeau S, Vereecken C, Blot S. Behavioral determinants of hand hygiene compliance in intensive care units. American Journal of Critical Care. 2010;19(3):230-239. https://doi.org/10.4037/ajcc2010892 